\title{
Interpreting Social Differentiation by Examining the House and Settlement Patterns and the Flow of Resources: A Case Study of Pai-wan Slate House Settlements in Southern Taiwan
}

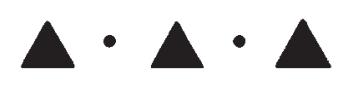

MAA-LING CHEN

\section{INTRODUCTION}

COMPLEXITy IN A SOCIAL SYSTEM is characterized by social differentiation, centralization of power, and hierarchical organization. As a consequence, archaeologists have generally looked for diversity in mortuary treatments, residential and public architecture, monumental constructions, craft specialization, and the distribution of imported or prestige goods as indicators of social differentiation, social control, and complexity in a particular social system. Recently, however, the range and degree by which rules and constraints regulate and coordinate the practices of daily and social life within and outside houses have also been regarded as indicators of where social control is embedded. In this study, it is argued that certain consistent repetitive patterns of house structure and settlement configuration, and the distribution of imported or prestige goods in a Pai-wan settlement, are the result of negotiation within the available natural setting and resources, as well as with the social rules, constraints, and structured flow of resources (land, materials, etc.) put in place in the daily and social practices of its inhabitants. It is expected that, through the examination of settlement and house structure, and the patterns, amount, and types of exchanged goods households possessed, the social system of Kau-shi, a South Pai-wan group, can be better understood and reconstructed.

\section{RESEARCH CONCEPTS AND THEME}

Space is a basic element of culture and a social phenomenon. It consists of both abstract and concrete properties of culture, and is embodied in the daily lives and activities of people. Its construction involves not only both natural geographic and man-made environments, but also various social relations, political or economic conditions, cultural customs, concepts of classification, cognitive structures, symbolic systems, and 
ideology (Y. Huang 1995:1-5). These properties shape people's conceptions of space and landscape, and further structure their activities and the material patterns they produce. In other words, space is incorporated in daily and culturally embedded social practices and social processes, which cannot be set apart from human activities. Spatial analysis focuses on documenting the nature, patterns, and configurations of human activities in places, households, communities, and landscapes, and is an essential methodology for reconstructing cultural and social aspects of human societies in the present and the past.

Complexity in a social system is characterized by social differentiation, centralization of power, and hierarchical organization. Social differentiation is mainly established by the diversity of power and contested rights for the accessibility to resources, and it is an indicator of heterogeneity in societies. Centralization of power and hierarchical organization have as their basis mechanisms of social control and manipulation of rituals and symbolism. All these involve the processes of group division and differentiation, dynamics and maintenance of social control, and formation of class identity (Costin and Hagstrum 1995; Trubitt 2000). Social differentiation is revealed by variation in social status and wealth. Centralization of power and hierarchical organization are indicated by the control of labor and resources. Materials, with their properties and visible presence, are involved in the processes of embodiment, manifestation, and extension of human bodies, ideas, social intentions, actions, and social relationships (Marshall 2008). Material culture is employed in these social processes, and therefore archaeologists have generally looked for diversity in mortuary treatment, residential and public architecture, the existence of monumental constructions, craft specialization, and the distribution of imported or prestige goods as indicators of social differentiation and social control, and as ways of identifying complexity in a social system (Trubitt 2000).

Differential access to certain resources indicates economic power, and legitimizes the transition from control over finances to control over sociopolitical processes (Costin and Hagstrum 1995). Variation in mortuary treatments, residential and public architectures, and presence of monumental constructions are significant and visible indicators for detecting these sociopolitical processes and the formation of materialization and symbolization of social control and political centralization. Monument structures are especially prime indicators. However, archaeologists have begun to recognize more variations in the nature and embodiment of complex societies and to reevaluate the role and form of symbolization of material in the context of social differentiation, social control, and centralization of power. As Hodder and others have recently debated, the mundane and social practices in daily life are primarily where the social rules, meanings, relations of power, and rituals are embedded (Hodder and Cessford 2004) for the purpose of social control and centralized coordination of functions. These scholars assert that domestic space can be the mechanisms through which people are socialized into particular rules and orientations; therefore, the household and the daily activities in the house are where the focus of attention should be in studies of social processes, social control, and centralization of power. The rules and constraints dealing with access to resources, refuse disposal, sanitation, social relations, ritual practices, and so on regulate the lives of the inhabitants of a community. People learn rules and constraints as they carry out their daily tasks within and outside the house, and these daily habits eventually become social practices. In this kind of linkage, the daily and social practices carried out within houses and communities, as well 
as around monuments and landscapes, are related to a particular form of relationship between people and particular forms of power.

Hodder and Cessford's analysis (2004) of social practices focused on spatial as well as temporal aspects. Their analysis considers past practices as a form of memory that repeats earlier practices. They argue that people are socialized in a house through two primary mechanisms: conducting repetitive daily practices and constructing social memory. They base their arguments on a remarkable continuity in the rebuilding of a house at the Neolithic site of Catalhöyük in Turkey, where the structure was rebuilt in exactly the same location, with the hearth and midden in identical places, and with the same internal arrangements of buildings over many years. They interpreted these patterns as representing the existence of a high degree of rule-bounded daily practices among the inhabitants, and further suggested that the intensive constraints and a certain level of centralization power had been developed at Catalhöyük.

Based on the research outlined above, this article argues in more detail that if the degree of repetition of daily and social practices indicates the level of social constraints and centralization of power, then the following suggestion can be made: the higher the social control and the more intensive the centralization of power, the higher intensity the daily social practices negotiates with and links to the form of power. Furthermore, the more the constraints regulate and shape people's ways of carrying out their daily or social tasks, the higher the public rituals codify and embed the practice of daily life as negotiations between individuals and complex interpersonal, intragroup, and intergroup relationships. Consequently, all these would be present through the intensity of the repetition of social practices on every aspect and over every space level, such as place, household, settlement, and landscape. In other words, the diversity in mortuary treatments, residential and public architecture, and the presence of monument constructions and craft specialization are no longer the only indicators that archaeologists could look for identifying social differentiation and complexity. The range and the degree by which the rules and constraints regulate and coordinate the practice of daily and social life within and outside houses would also be regarded as indicators to explore the centralization of power and where social control is embedded.

The slate house structure is one of the remarkable cultural characteristics of the Pai-wan ethnic group in Taiwan. This study argues that the characteristics of slate house structures in the Pai-wan settlements, including their shape, size, and features, the domestic activities arranged in a household, the way the house structures are arranged in a settlement, and so on are all linked to the social practices of the Pai-wan groups. The social practice and construction of social memory would be embedded, presented, and embodied in the house structures. The social system of the settlement's inhabitants might be determined by examining the nature and characteristics of the house structures. How a slate house should appear, what its size should be, how people carry out and arrange their domestic activities within and outside a house or in public areas, and how these slate houses should be arranged over a settlement and landscape are all the results of negotiation with the available natural setting and resources, but also with the social rules, constraints, and structured flow of resources (land, materials, etc.) learned and obtained from the daily social practices of the inhabitants. This will be also corroborated with an examination of variation in the distribution of house sizes, as well as exchange of prestige goods in the structures, to evaluate the idea that social stratification can be seen in the differentiation of power to access 
various resources. Exchanged goods, especially prestige goods, and the power to manipulate the exchange network, are regarded as media for expressing social status and maintaining social differentiation. Therefore, examining and comparing the amounts of prestige goods that households hold are regarded as ways to detect the social status of households in a society.

\section{AN OVERVIEW OF THE PAI-WAN CASE AND ARCHAEOLOGICAL ANALYSES}

The Pai-wan group is one of many ethnic groups in Taiwan (see Fig. 1). It is classified into the North, South, and East subgroups (see Fig. 2). Based on oral histories and ethnographic studies, a general picture has been drawn to illustrate several population movements from the north to the west and south, and then to the east, where these people are settled today. One of the well-known characteristics of the Pai-wan culture is its slate house structures. Many abandoned settlements with slate house structures have been found in Ping-tun District, where the Pai-wan groups (North and South) have mostly settled (see Fig. 2). Only the locations have been recorded, but no further studies have been made nor is there much information about these known sites.

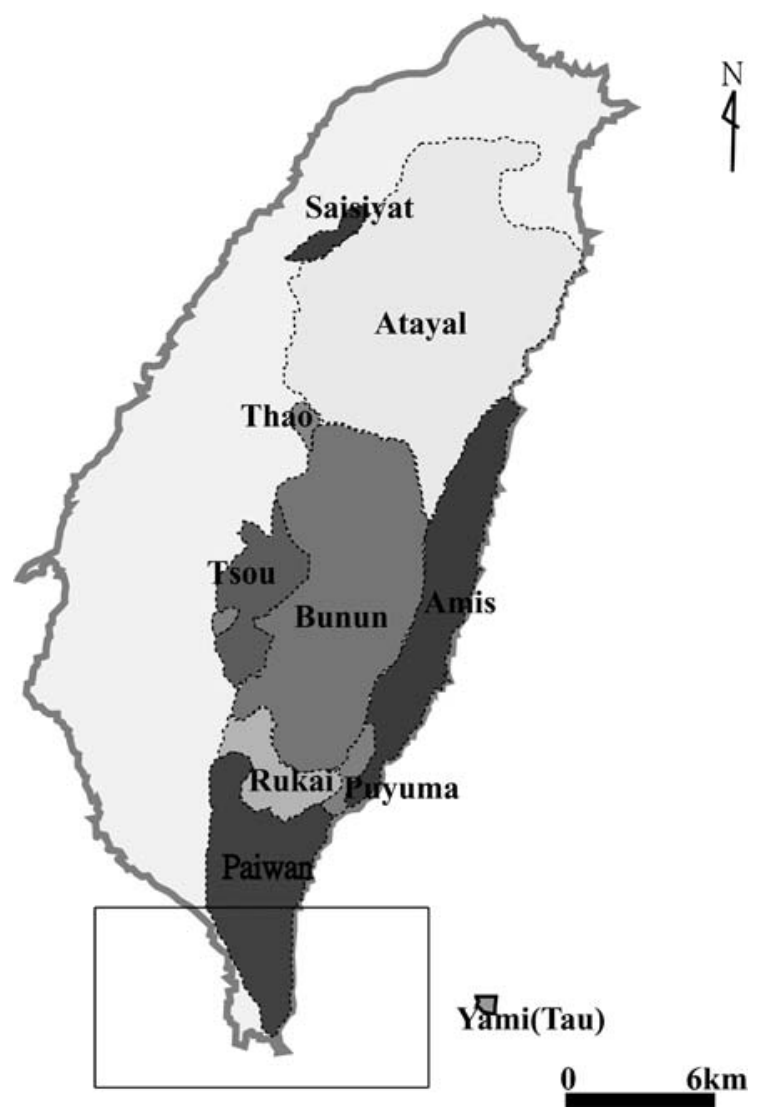

Fig. 1. Distribution of major ethnic groups in Taiwan. 


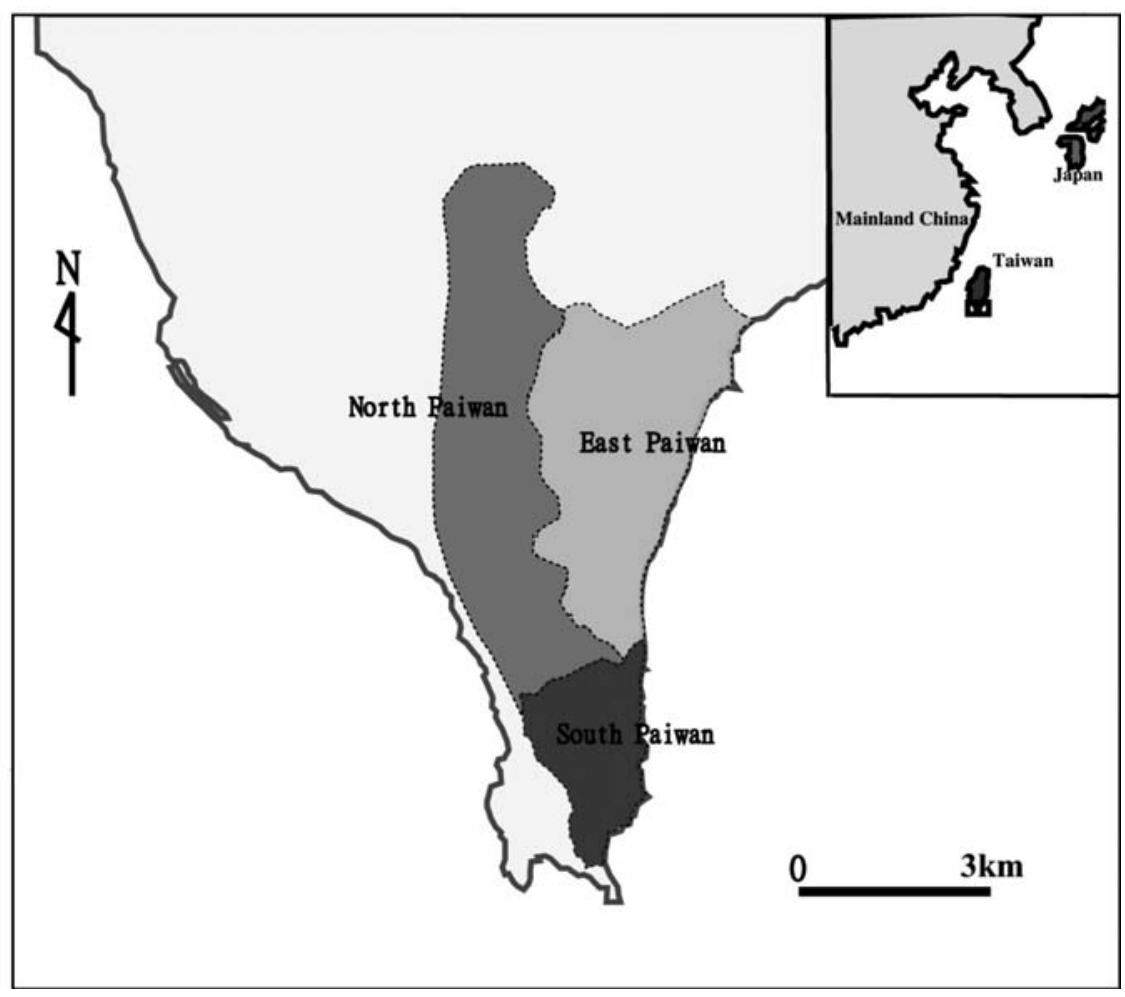

Fig. 2. Location of the study area and the distribution of Pai-wan subgroups.

Most scholars believe that all the different Pai-wan subgroups came from the North Pai-wan group due to population disintegration and migration of people to different regions. The South Pai-wan group was believed to have branched off from the West Pai-wan group and to have immigrated to the $\mathrm{Mu}$-dan County in the later period. After the South Pai-wan group came into contact with the Japanese and the Han Chinese, its cultural traditions were heavily influenced and thus significantly changed. Because of this, most of the research has focused on the North Pai-wan group, and studies on the South Pai-wan group have been rare and fragmentary.

Japanese scholars were the first to study the settlements and architectures of the indigenous groups in Taiwan. Their works, especially Suketaro Chijilwa's (1937), contain very detailed descriptions, drawings, and photographs of the various types of ethnic architecture that form a solid foundation for academic research. Since then, much of the research on Pai-wan settlements and architecture has been conducted by architects and, in a few cases, by anthropologists (Chiang 2002; Chiang and Li 1995; Chien 1995; Chijilwa 1937; C. Huang 1982; K. Hsu 1993; S. Hsu 1996; C. Li 1994; Y. Li and C. Wu 1982; Lin 1994; Tseng 1991). Most of the research has focused on the North Pai-wan group because this group has been regarded as the originator of the architectural structures for all of the Pai-wan subgroups.

In comparison with what has already been documented about the North Pai-wan, this study focuses on the three South Pai-wan settlements having slate house structures 
(i.e., the Saqacengalj, Cacenvakan, Aumagan settlements) to gain a deeper understanding of the role of slate house structures in the Pai-wan culture. The approach emphasizes the examination of house pattern, settlement configuration and the distribution of non-local or prestige goods in order to explore the social system. The house and settlement constructions are where social practices are carried out and through which social memory is constructed and presented.

\section{Sites Studied}

Saqacengalj, which literally means a "tool for drilling slates," is located on the forested uplands in Mu-dan County, Pin-dong District at the southern tip of Taiwan, at $22^{\circ} 09^{\prime} 07^{\prime \prime} \mathrm{N}, 120^{\circ} 51^{\prime} 25^{\prime \prime} \mathrm{E}$ (see Fig. 3). At an elevation of 250 to $300 \mathrm{~m}$, the settlement is built on a flat slope and is oriented along an E-W ridge, which is about $140 \mathrm{~m}$ long from east to west and $100 \mathrm{~m}$ long from north to south, its area being $14,000 \mathrm{~m}^{2}$ (1.4 ha). It includes more than 10 terraces with more than 83 slate architectural structures. ${ }^{1}$

Cacevakan is located on a forested slope facing north at $22^{\circ} 06^{\prime} 16^{\prime \prime} \mathrm{N}, 120^{\circ} 48^{\prime} 11^{\prime \prime} \mathrm{E}$, at an elevation of 320 to $350 \mathrm{~m}$. The settlement is spread across five terraces and consists of 15 house structures. The exact extent of the settlement is still unknown because accessibility to the nearby forest is limited, and a comprehensive investigation of the site cannot be carried out.

Aumagan is located in an upland area near Chunchai village at $22^{\circ} 07^{\prime} 59.9^{\prime \prime} \mathrm{N}$, $120^{\circ} 48^{\prime} 13.49^{\prime \prime} \mathrm{E}$, at an elevation of 326 to $226 \mathrm{~m}$. The settlement is about $140 \mathrm{~m}$ long from south to north and $100 \mathrm{~m}$ long from east to west, and is on a slope oriented along an S-N ridge with 11 terraces consisting of more than 64 house structures.

Oral history specifies that these three sites belong to the ethnic group Kau-shi, which is one of the South Pai-wan subgroups. Accordingly, the Kau-shi group was divided into two subgroups when they immigrated to the Hun-chun area (see Fig. 3). One of these two subgroups settled at Saqacengalj, while the other moved farther along a stream and settled on Cacevakan. (However, some informants from the area have said that the site should be related to another South Pai-wan subgroup.) After several generations, the two subgroups merged and established another settlement called Aumagan. According to the oral history, Saqacengalj has existed for 500 to 600 years since the Kau-shi immigrated to the southern area. There are some ${ }^{14} \mathrm{C}$ datings from Saqacengalj showing that the people abandoned the settlement about 350 years ago (Chen 2005). The exact date and duration of the establishment and occupation of the settlement is still unknown. The same is true for Cacevakan and Aumagan. The dates, the accuracy of the oral history, and the status of the three sites should be verified by further archaeological studies.

The settlement configurations and house structures of these three sites have been mapped out (Figs. 4-6), analyzed, and compared with the nature and characteristics of the settlements. Furthermore, the results of these studies have been compared to those of the studies on the North Pai-wan settlements. This study is an attempt to identify the similarities and differences of the house structures and settlements of the Pai-wan in different areas to gain a better understanding of the overall diversity and characteristics of the structures of the Pai-wan slate houses and settlements over the larger region. 


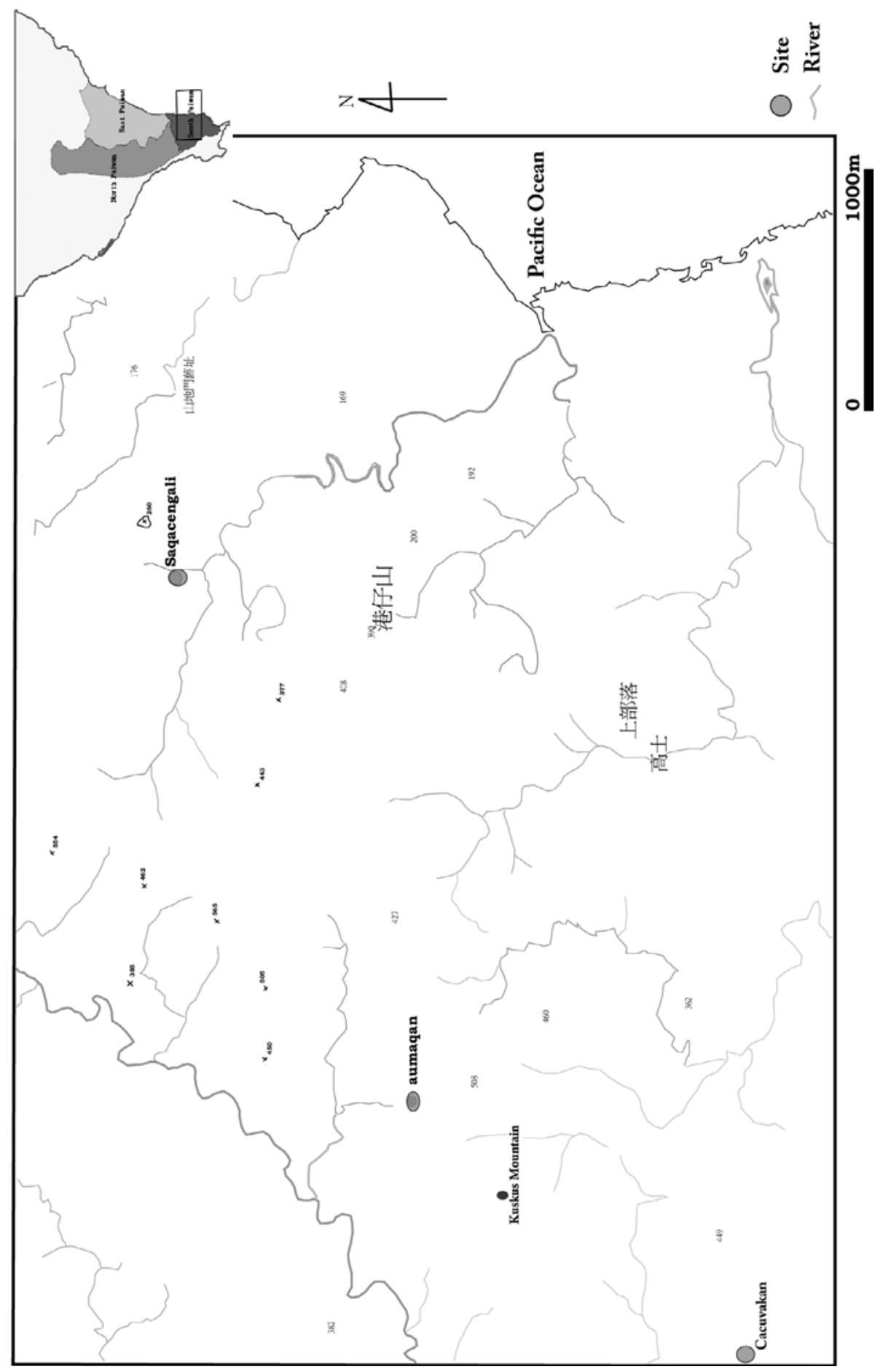




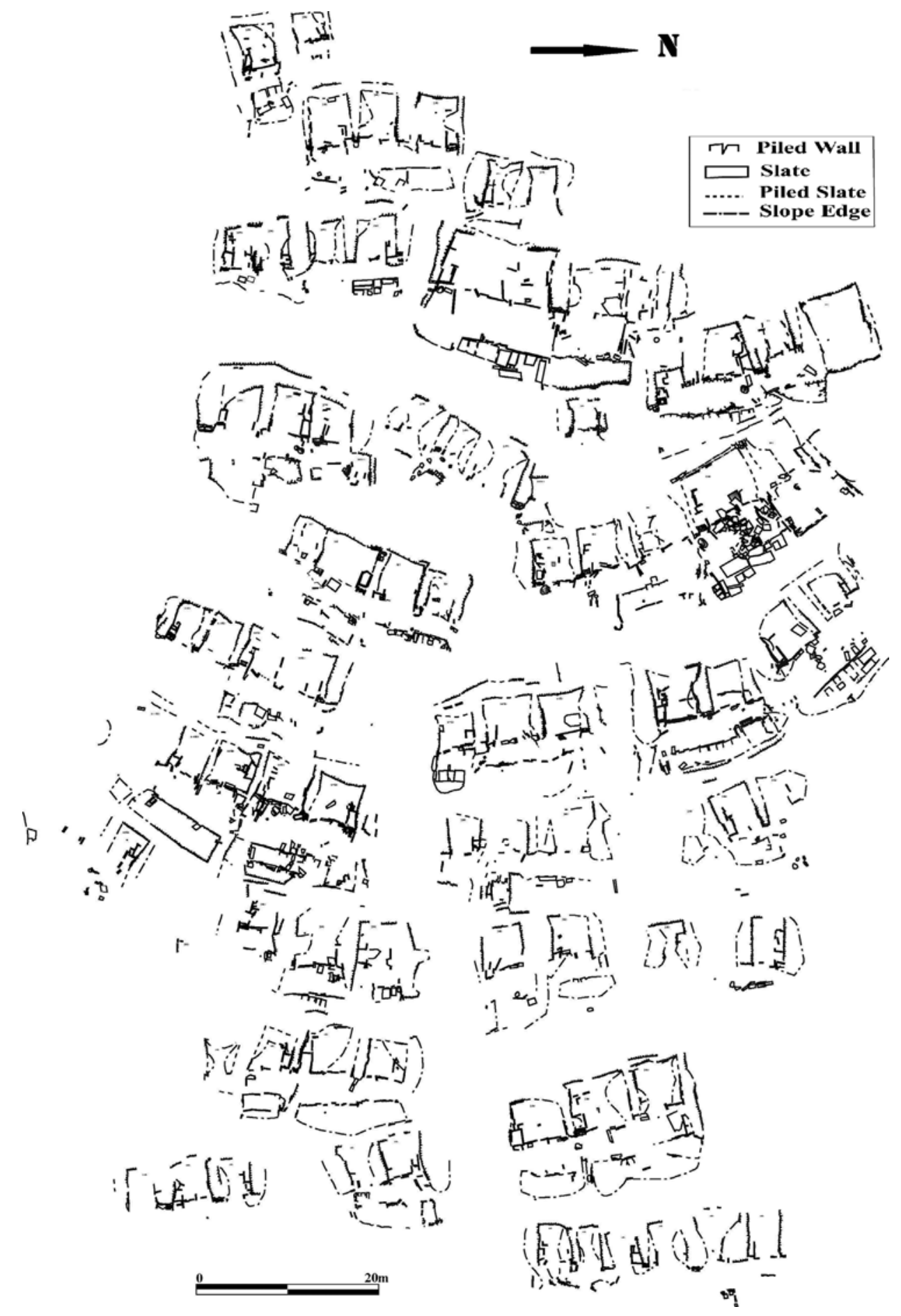

Fig. 4. Settlement configuration of Saqacengalj. 

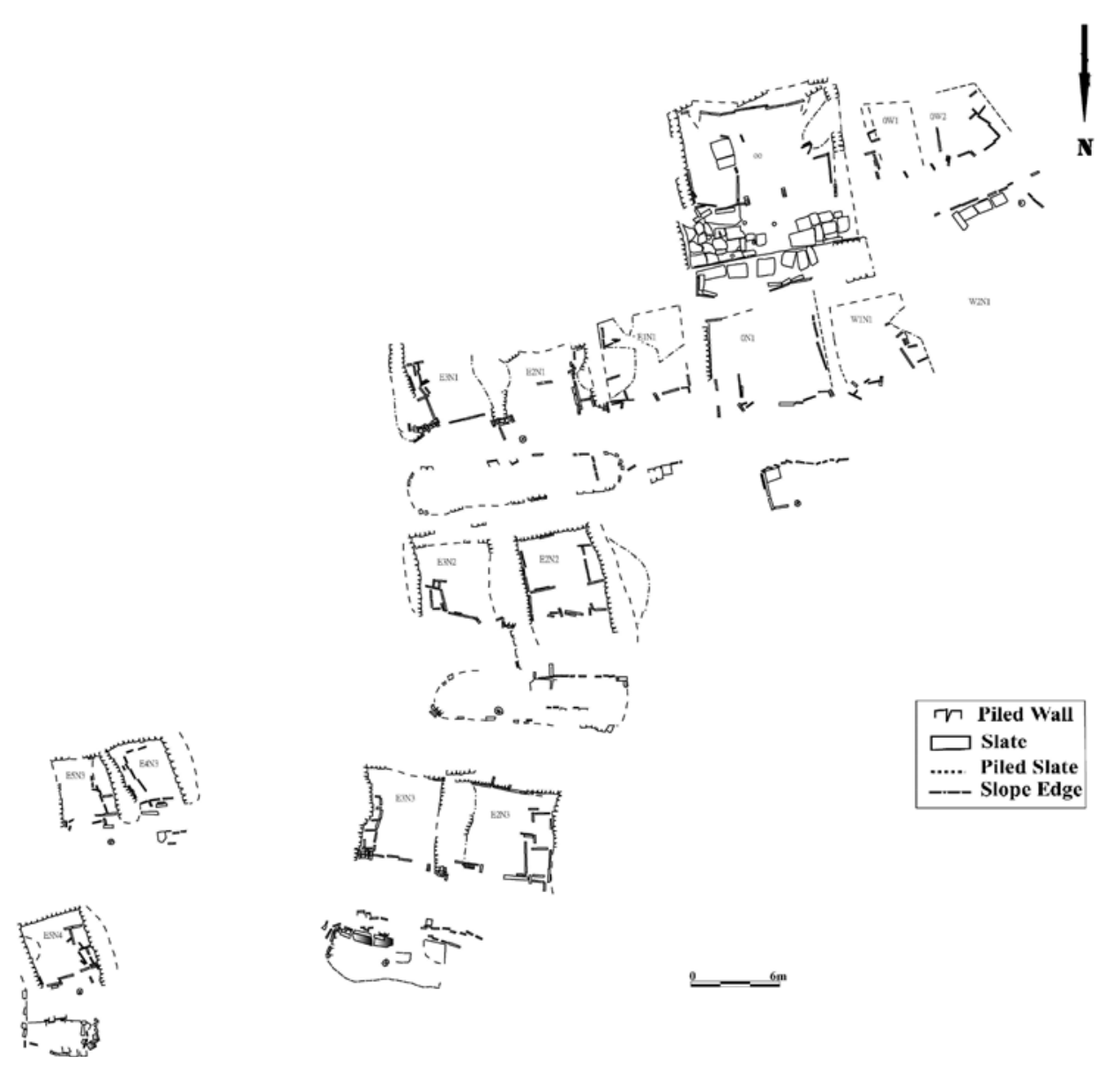

Fig. 5. Settlement configuration of Cacevakan.

\section{Characteristics and Similarities of the Settlement and House Structures}

A synthesis of the characteristics of the settlements and architecture at these three sites can ascertain the sites' similarities and differences. Some aspects of the shared similarities are consistent with those of the Pai-wan group, as represented by the North Pai-wan subgroup. Given this, it is possible to discuss the nature of the settlements and house structures of certain South Pai-wan subgroups.

Current and previous studies have revealed common characteristics of these three settlements. The settlements are located in mildly sloped areas in mountain woodlands. There are stone-slate house structures of various kinds - including floors, walls, roofs, poles, and even internal structures - arranged parallel to numerous slope terraces, adjacent to each other with a shared wall, and usually set against the slope facing the valley. The house structures have a foundation with an L-shaped cross section formed by cutting into the terrace and building the rear and side walls against the excavated portions.

The lack of doorways connecting individual houses suggests that house structures were spatially independent from each other. House structures at these three sites have 


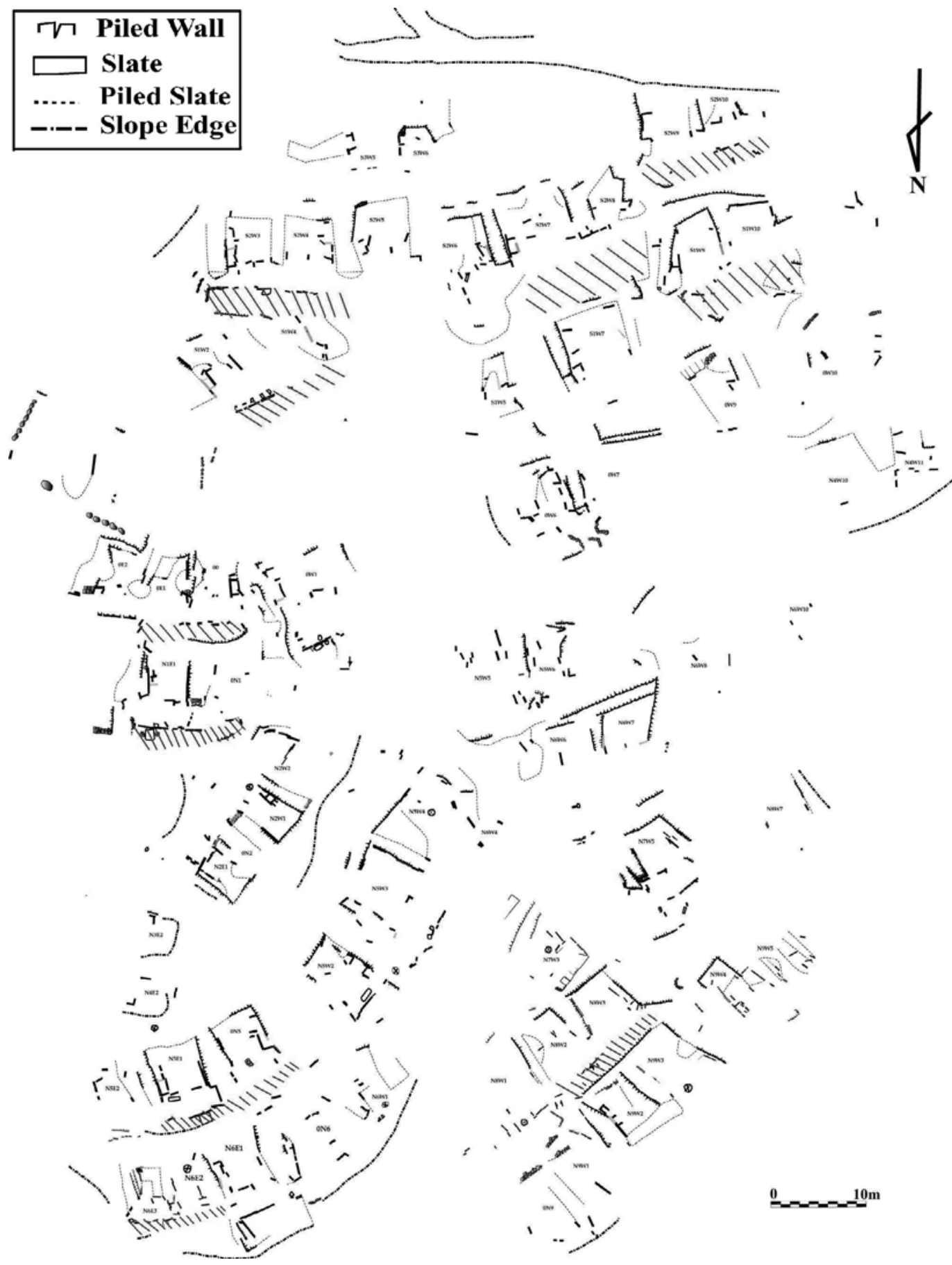

Fig. 6. Settlement configuration of Aumagan. 
Table i. Distribution of Different House Shapes at the Three Sites

\begin{tabular}{|c|c|c|c|c|c|c|}
\hline \multirow{4}{*}{$\begin{array}{l}\text { SITE } \\
\text { Saqacengalj }\end{array}$} & \multicolumn{6}{|c|}{ HOUSE SHAPE } \\
\hline & \multirow{2}{*}{\multicolumn{2}{|c|}{$\begin{array}{l}\text { VERTICALLY } \\
\text { RECTANGULAR }\end{array}$}} & \multirow{2}{*}{\multicolumn{2}{|c|}{$\begin{array}{l}\text { HORIZONTALLY } \\
\text { RECTANGULAR }\end{array}$}} & \multirow{2}{*}{\multicolumn{2}{|c|}{ SQUARE }} \\
\hline & & & & & & \\
\hline & $73 / 83$ & $88 \%$ & $7 / 83$ & $8.4 \%$ & $3 / 83$ & $3.6 \%$ \\
\hline Cacevakan & $7 / 15$ & $47 \%$ & $3 / 15$ & $20 \%$ & $5 / 15$ & $33 \%$ \\
\hline Aumagan* & $35 / 50$ & $70 \%$ & $12 / 50$ & $24 \%$ & $4 / 50$ & $8 \%$ \\
\hline Lai-yi & $23 / 215$ & $10.7 \%$ & $181 / 215$ & $84.2 \%$ & $11 / 215$ & $5.1 \%$ \\
\hline
\end{tabular}

* Due to uncomplete preservation of the structures on Aumagan, only 50 units are included in the analysis.

Table 2. Distribution of Platforms, Pairs of Houses That Share a Platform, and Pairs of Houses That Share a Platform with Structures in a Left/Right Pattern at THE Three Sites

\begin{tabular}{|c|c|c|c|c|c|c|}
\hline & & & & & \multicolumn{2}{|c|}{ PAIRS OF HOUSES } \\
\hline & & & & & \multicolumn{2}{|c|}{ SHARING A } \\
\hline & & & & & \multicolumn{2}{|c|}{ PLATFORM AND } \\
\hline & & & \multicolumn{2}{|c|}{ PAIRS OF HOUSES } & \multicolumn{2}{|c|}{ STRUCTURES IN } \\
\hline & & & \multicolumn{2}{|c|}{ SHARING A } & \multicolumn{2}{|c|}{ LEFT/RIGHT } \\
\hline & & & \multicolumn{2}{|c|}{ PLATFORM/TOTAL } & \multicolumn{2}{|c|}{ PATTERN/PAIRS OF } \\
\hline & \multicolumn{2}{|c|}{ PLATFORM/TOTAL } & \multicolumn{2}{|c|}{ STRUCTURES WITH } & \multicolumn{2}{|c|}{ HOUSES SHARING A } \\
\hline SITE/STRUCTURE & \multicolumn{2}{|c|}{ STRUCTURES } & \multicolumn{2}{|c|}{ PLATFORM } & \multicolumn{2}{|c|}{ PLATFORM } \\
\hline Saqacengalj & $64 / 83$ & $77 \%$ & 13 pairs & $41 \%$ & $9 / 13$ & $69 \%$ \\
\hline Cacevakan & $14 / 15$ & $93 \%$ & 5 pairs & $71 \%$ & $5 / 5$ & $100 \%$ \\
\hline Aumagan & $32 / 64$ & $50 \%$ & 10 Pairs & $63 \%$ & $3 / 10$ & $30 \%$ \\
\hline Lai-yi & $12 / 215$ & $5.6 \%$ & & & & \\
\hline
\end{tabular}

vertical rectangular shapes rather than horizontal rectangular shapes (see Table 1). Besides the house structures per se, there are other kinds of slate structures, such as front yards, ditches, platforms, and platform-attached structures. In front of most structural units, there is a rectangle platform, varying in size, formed by stone slates. While some structural units have individual platforms, some adjacent structures share a platform that stretches from one end of a unit to the end of another unit without any clear dividing feature. Analysis shows that a high percentage of structures with attached platforms (see Table 2) is characteristic of these three settlements. In other words, having an attached platform is a common feature among the house structures in the three settlements.

Some slates appear to have been assembled purposely into various features in different locations inside the units. Some of the two units sharing a sidewall and platform have small rectangular features located within the left part of the left unit and within the right part of the right unit. Based on Table 2, 9 out of 13 (or 69\%) pairs of houses in Saqacengalj, 5 of 5 pairs (100\%) in Cacevakan, and 3 of 10 pairs (30\%) in Aumagan, share a platform and a small structure inside each house with a left/right correspondent pattern (see Fig. 7). Rather than representing a sampling error, these numbers show that a common feature shared by the three sites (although in different frequencies) is that of pairs of house structures sharing a platform and having a feature inside 


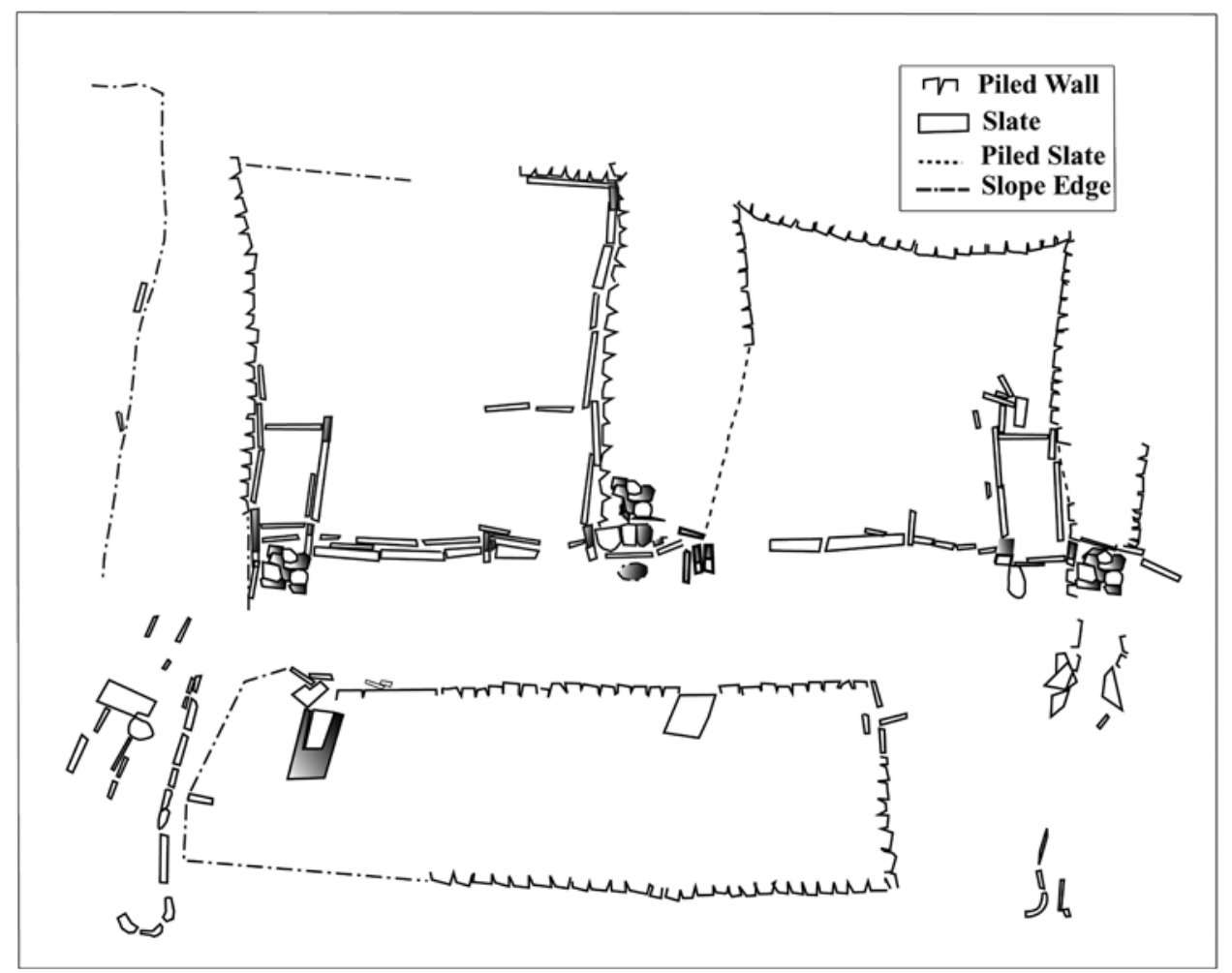

Fig. 7. A pair of house structures with inner features located in the left/right corresponding pattern.

each house arranged in the left/right correspondent pattern, a patterned spatial arrangement that may have significant meaning in Pai-wan societies. Whether the diversity in the percentage of the features at these three sites indicates some variation in their meaning or was caused by different preservation conditions of the structures at the sites remains a question that needs to be explored further by analyzing more data on the house structures (Figs. 8-10). Besides the small rectangular features, there are possible underground grave pits located inside some units (for a more detailed illustration of the settlement configuration and house structures, see Chen 2008).

\section{DISCUSSION}

Many of the preceding studies on the North Pai-wan subgroups show that the houses are either single or compound structures and have a horizontal rectangular shape rather than a vertical rectangular shape. A platform attached to a house structure, attached structures, symbolic poles, engraved decorative structural items, and Ficus microcarpa trees, as well as the size of the houses and front yards, was used to indicate the status of the chief or of elites and functioned as a place for meetings or rituals (Chiang 2002; Chiang and Li 1995; Chijilwa 1937; S. Hsu 1996; Kau 2003; C. Li 1994; Y. Li and C. Wu 1982; Lin 1994; Wu 1994). However, having a platform attached to a house structure is a common feature at these three sites, 


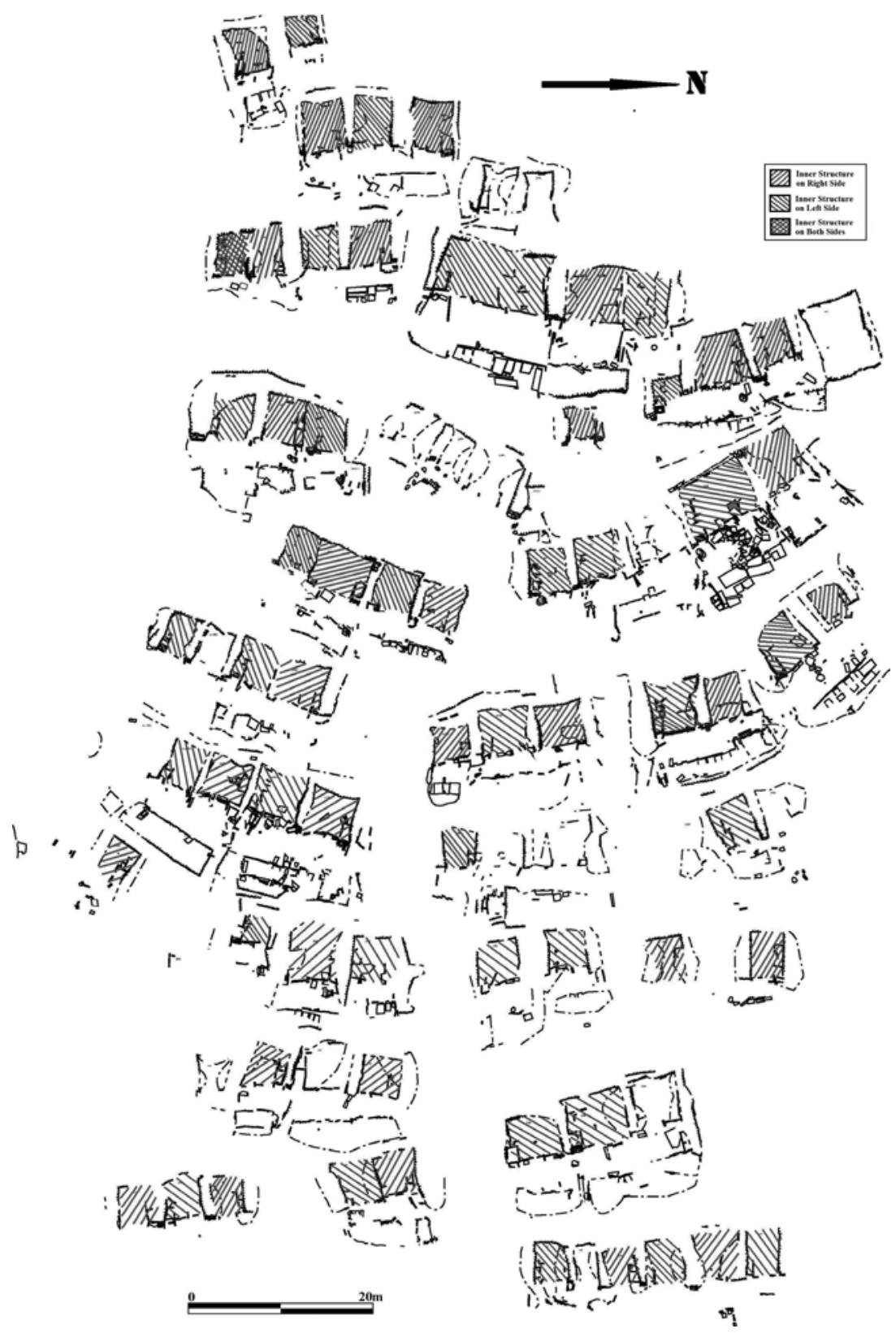

Fig. 8. The left/right or right/left corresponding pattern of inner structures at Saqacengalj.

and is not highly restricted to a few houses. Obviously, the platforms at these three sites must have served different purposes than suggested by these popular interpretations of the characteristics of the North Pai-wan settlements. In the case of the investigated South Pai-wan settlements, the platforms cannot be reasonably interpreted as a symbol of social status and a place for meetings or rituals. 

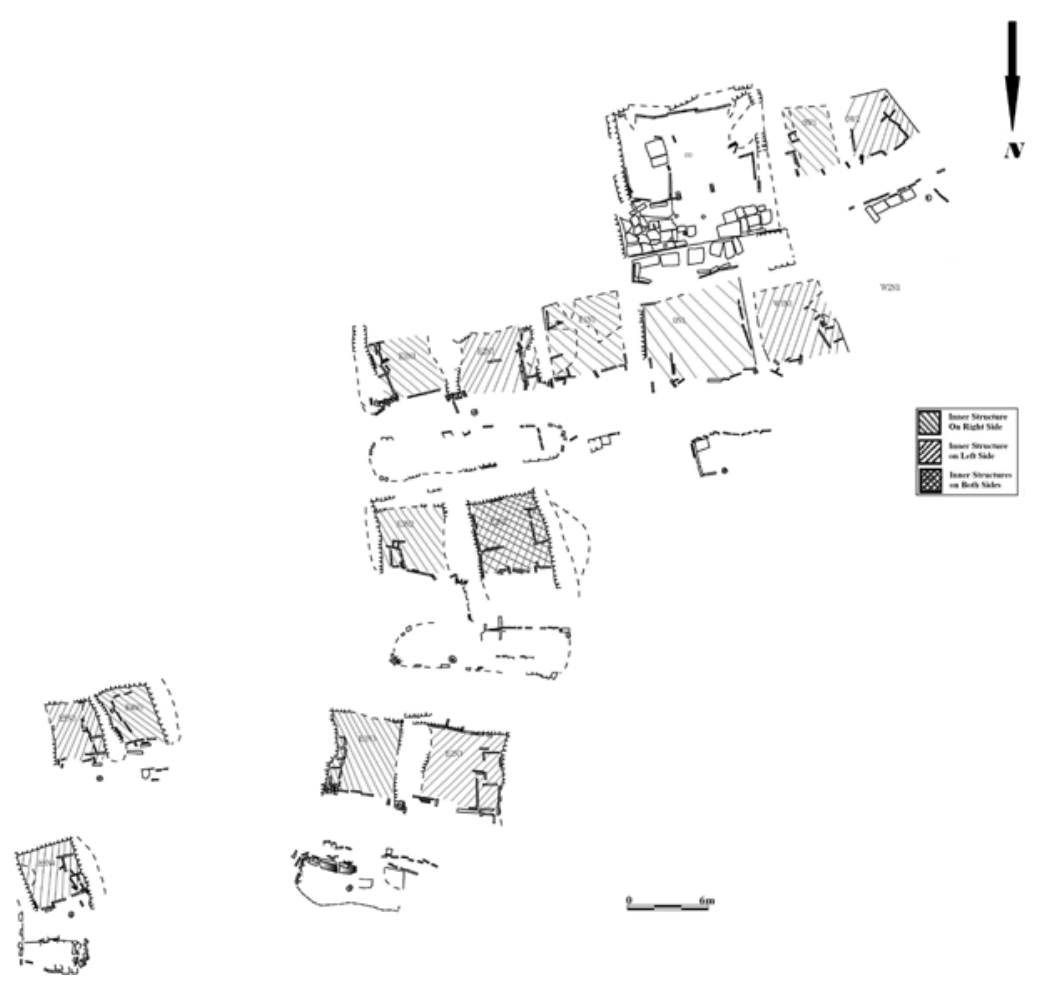

Fig. 9. The left/right or right/left corresponding pattern of inner structures at Cacevakan.

Based on comparisons, architectural forms vary among the subgroups and settlements of the South and North Pai-wan groups. If the topography of a settlement, typically a mild slope with several terraces, is the primary determining factor in architectural design, it is more rational for residential units to be designed in "horizontal rectangular" forms in order to gain more household space (such as those at the North Pai-wan settlements; see Table 1), because the depth of the terrace is limited. However, conversely, the primary form of structural units at these three settlements is vertical rectangular, defying what would be predicted from topography considerations alone. Does this indicate that the inhabitants of these three settlements have certain consistent concepts about how their houses should be oriented and laid out, even against the seeming constraints of land space?

Old Lai-yi, the representative settlement of the North Pai-wan subgroup, is located on a slope where the terraces are steeper and deeper compared to the ones at the studied sites (see Table 3). However, the front yards of some house structures are narrow, almost like a pathway between the houses and the edge of the terrace, and leave no extra space on the terrace for a platform to be built. The terraces on the slopes where the three sites are located are flatter and shallower compared to the ones at the Old Lai-yi settlement (see Table 3). Nevertheless, the terraces, besides having house structures constructed on them, have space large enough for every house structure to have a larger front yard and a platform. At the same time, when the shape and depth of the house structures at Old Lai-yi and at the sites studied are compared, Old Lai-yi 


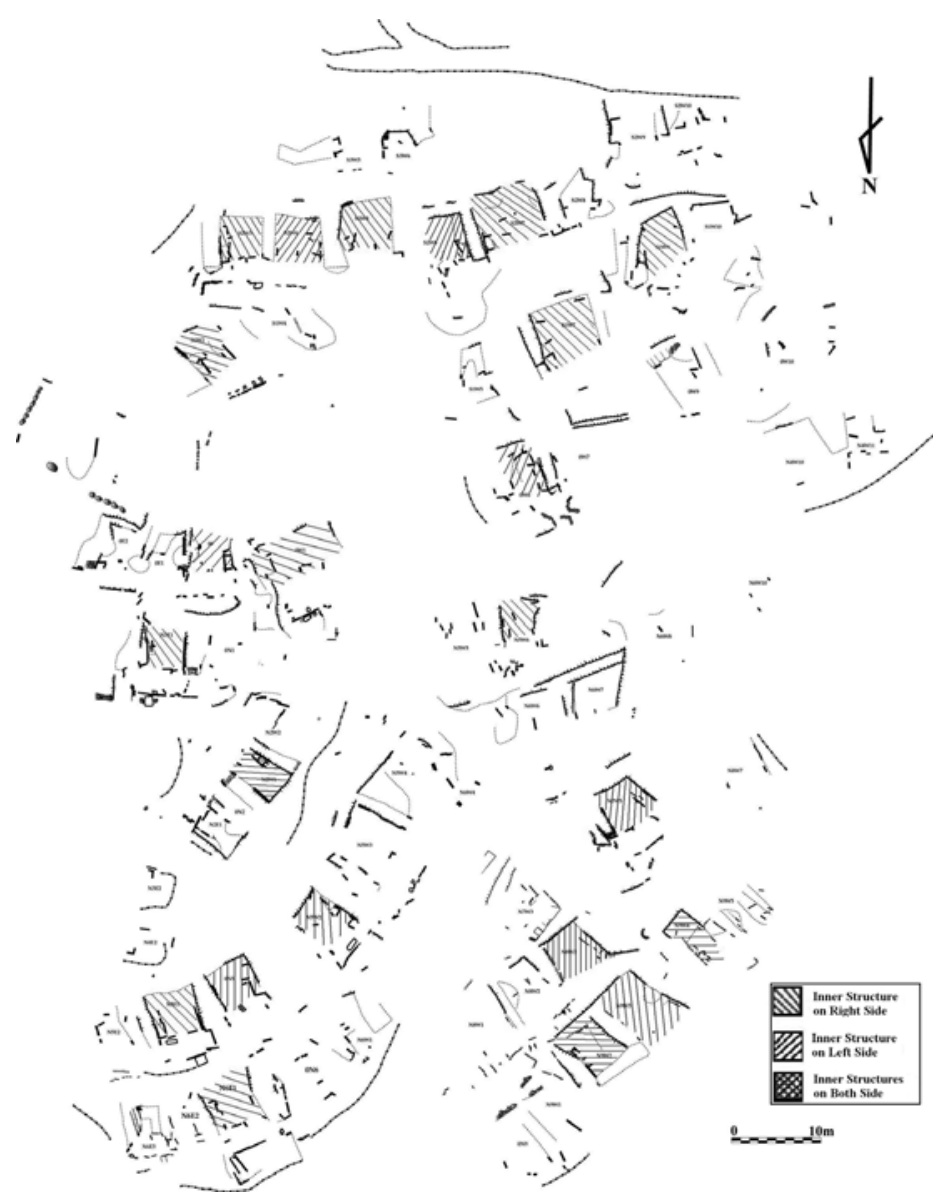

Fig. 10. The left/right or right/left corresponding pattern of inner structures at Aumagan.

reveals a pattern that is distinct from the studied sites: the house structures of Old Laiyi are horizontally rectangular in shape (see Table 1), and the minimum, maximum, and average depth of the house structures at Old Lai-yi are all larger. This indicates that the Old Lai-yi group may have preferred a bigger space for a house than for a front yard or a platform (see Table 4), while the groups at the three studied sites favored the opposite. These differences were obviously the result of the different choices made based on the people's cultural preferences. The differences were the result of the different views on what the settlement and the house structure should be like. While one group recognized that having a front yard and a platform attached to the house structure was ideal, the other group had a different view or was constrained to having a big front yard and a platform attached to a house structure and used this to express certain social meanings, such as social status. If this observation is indeed correct, does this mean that the inhabitants of the studied sites, referring to certain South Pai-wan groups, did not have a social hierarchy or did not use attached platforms as an indicator of social status, but instead utilized different ways to show hierarchy? What were the processes and contexts that caused this difference? 
Table 3. Depth of Terraces at the Sites

\begin{tabular}{lcccc}
\hline Site/DePTH & Minimum $(\mathrm{M})$ & MAXimum $(\mathrm{M})$ & AVERAGE $(\mathrm{M})$ & STDEV \\
\hline Saqacengalj & 4.8 & 16 & 10.5 & 2.74 \\
Cacevakan & 6 & 14 & 11.5 & 2.3 \\
Aumagan & 4.4 & 15 & 9.8 & 2.13 \\
Old Lai-yi* & 8.45 & 15.6 & 10.8 & 2.57 \\
\hline
\end{tabular}

* only where $11 \%$ of the structure units located were measured.

Table 4. Depth of House Structures at the Sites

\begin{tabular}{lcccc}
\hline Site/DePth & Minimum $(M)$ & MAXimum $(M)$ & AVERAGe $(M)$ & STDEV \\
\hline Saqacengalj & 3.18 & 7.55 & 4.55 & 0.74 \\
Cacevakan & 4.15 & 7.38 & 5.48 & 1.03 \\
Aumagan & 1.66 & 8.46 & 5.15 & 1.27 \\
Old Lai-yi & 4.8 & 9.5 & 6.46 & 0.8 \\
\hline
\end{tabular}

As illustrated in the historical literature, the Pai-wan were a ranked society during the Dutch and Japanese occupations. The oral history of the Kau-shi group also characterizes Saqacegalj as a stratified society when its residents moved out of the settlement (Chen 2005). Thus, can we regard the sites studied as having had a stratified social system? What would the archaeological data suggest?

If the topography of a settlement - typically a mild slope with several terraces - is the determining factor in architectural design, it is more rational for residential units to be designed as "horizontal rectangular" forms in order to gain more household space (such as the Old Lai-yi settlement shows) because the depth of the terrace is limited. However, conversely, the primary form of structural units at these three settlements is vertically rectangular. Moreover, there is even space for bigger front yards and platforms to be built, restricting the house sizes more. This would indicate that the inhabitants of these three settlements had particularly consistent concepts about how their houses should be oriented and laid out. Social constraints shaped the house form and limited the people's choice, if only to make the pattern constant and consistent through time.

As the theoretical concept stressed previously shows, the social practice in daily life would primarily be where the social rules, meanings, and relations of power and rituals are embedded for social control and centralized coordinating functions. The range and degree that the rules and constraints regulate daily and social life would be regarded as the indicators of the social control and centralization of power. Although this study has not been able to explore the domestic activities in the house structures to address the social practices embedded in the activity patterns in daily life, the patterned behaviors of arranging settlements and building houses should indicate certain social tasks and practices and provide material for discussion. House structures are set on land, and a settlement is arranged over the landscape, defining how people arrange their domestic and social lives within and outside these structures according to their shape, size, and layout. The shape and size of the house structures, the way certain features are arranged inside or outside a house structure, the size of the front yard, and 
the presence or absence of a platform would shape the people's sense of direction, their concept of space, the way their bodies moved, the way they organized their daily and social activities, and the interaction with others both inside and outside a house structure and in public areas. These could also be aspects that could be used to examine the construction of personhood, socialization, and daily and social practices. Therefore, it is argued here that the highly repetitively patterned distribution of the forms and patterns of house structures at the three sites may reflect the strong and intensive social constraints on and regulations for the appearance of the houses and the settlements built. The more highly patterned the house structures are, the stronger the social rules constrain people's behavioral choices.

In addition, a settlement, to a certain extent, would have experienced stages of establishment, growth, expansion, and abandonment. Various patterns consistent over the settlement and among settlements might indicate that the inhabitants repeatedly and continuously used the same rules, methods, and ideas for house and settlement construction through time, through different stages of development of settlements, and over different areas. This would imply not just that certain social constraints regulated the settlement but also that certain social identities and social memory would have been constructed through and embedded in the practices of the settlement and house structure construction. By practicing the same rule-bounded regulations to create the same forms of settlements and house structures, the inhabitants connected themselves to one another and to the past, to their earlier generations.

\section{Two Other Lines of Evidence}

Social differentiation is explored through variations in social status and wealth, and the degree of the centralization of power and hierarchical organization would be indicated by the control of labor and resources. Based on the effects of system integration, a high degree of system (either political or economic) integration indicates a strong centralizing and coordinating control and constraint regulating the flow of resources (Johnson 1980). The more the power regulates the flow of resources, the more distinct the accessibility people have to the resources. Therefore, the distributions of house size and imported or prestige goods can be examined to detect the variation in the accessibility to resources.

\section{Distribution of House Sizes}

An approach that emphasizes that the integration of the functions of social control and centralization of power to regulate and coordinate house construction through social practices, suggests that house size should be the result of negotiation based not only on the available natural resources but also on social rules, constraints, and the control of the flow of resources (land, materials, etc.). Therefore, it is expected that the degree of social control and constraint that regulates the flow of resources (especially land, manpower, and construction materials for the house structures) in a settlement would affect the size distribution of house structures.

An examination of the size distribution of the house structures at Saqacengalj and Aumargan (Cacuvakan was excluded in this examination due to incomplete sample) further addresses whether social differentiation was already developed at these two settlements. The size distributions of the house structures at the two sites are shown in 
Table 5. Statistics Summary of House Sizes at the Two Sites

\begin{tabular}{lcccr}
\hline SiTE/HOUSE SIZE & MAXIMUM M $^{2}$ & MINIMUM M $^{2}$ & AVERAGE $M^{2}$ & STDEV \\
\hline Saqacengalj & 72.44 & 3.89 & 18.27 & 8.99 \\
Aumagan & 57.13 & 4.17 & 25.64 & 12.68 \\
\hline
\end{tabular}
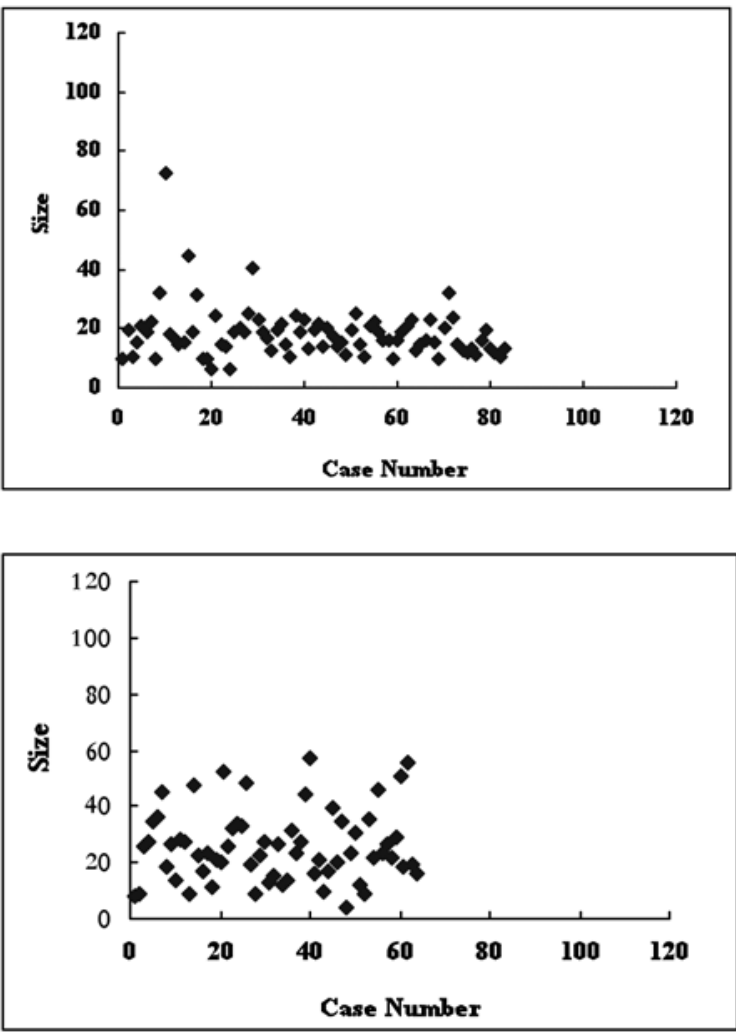

Fig. 11. The distribution of structure sizes at the Saqacengalj and Aumagan sites (top: Saqacengalj; bottom: Aumagan).

Table 5 and Figure 11. The size distribution of the house structures at Saqacengalj shows that 93 percent of the houses were smaller than $30 \mathrm{~m}$ in size, and, among them, 63 percent of the houses were 10 to $20 \mathrm{~m}^{2}$. Among the rest, one house is larger than $40 \mathrm{~m}^{2}$, while another is much larger than the others, being more than $70 \mathrm{~m}^{2}$. The size distribution of the house structures at Aumagan shows that 86 percent of the houses are less than $40 \mathrm{~m}^{2}$ in size, 70 percent of these houses are less than $30 \mathrm{~m}^{2}$ in size, and the rest were distributed between $40-50 \mathrm{~m}^{2}$ and between $50-60 \mathrm{~m}^{2}$.

The size distributions of the house structures of the two studied sites are clustered highly within a certain range, with other sizes that are few in number and that stand out. This might indicate that a certain degree of centralization of power and social control regulated and coordinated the flow of resources, materially reflecting the social differences between different groups in the settlements. Most of the inhabitants had limited resources and were allowed to build houses under a certain size. By con- 
trast, a certain small group of people, such as the elite and the chief, controlled almost all the resources through economic as well as political processes. Consequently, they could build houses the size they preferred in order to show their status and wealth.

\section{Variation on the Distribution of Imported or Prestige Goods in the House Units}

The degree of social control and constraint on the flow of resources in a settlement, especially land, manpower, construction materials for the house structures, and goods from exchange or trading networks, might have been reflected in variation in the distribution of certain types of archaeological artifacts in the settlement. Another line of data for examining regulation or constraint in the flow of resources at Pai-wan sites is an examination of variation in the spatial distribution of imported or prestige goods.

Two units (0S1 and 0S6) in Saqacengalj have been excavated, and the material remains recovered were used in the following analysis. Bronze artifacts, iron artifacts, and beads (material unknown), as well as some pottery, have been discovered from these two units (see Figs. 12 and 13). Specific pottery types have been identified as imported goods from an examination of morphological styles and composition, the latter from petrographical analysis (Chen 2008, 2010). To date, ethnographic and ethnohistoric studies have not produced data suggesting the local (Taiwan) manufacture of bronze and iron artifacts in the region (although certain evidence has been found in prehistoric sites to indicate the manufacture of iron), and therefore, any artifact made of these materials has to be regarded as imported and a probable prestige good. The nature of the raw material of beads is unknown; however, beads have been regarded as valued goods among these ethnic groups. Although the values of some of these artifacts are still uncertain, they can be used as a correlate of the regulation and coordination of the flow of resources from exchange or trading networks. Therefore, the distribution of these artifacts is used to evaluate the variation of wealth or the accessibility to special resources between household units. The result is presented in Table 6: Unit OS1 has 7 types and a total of 11 pieces, while 0S6 has 8 types and a
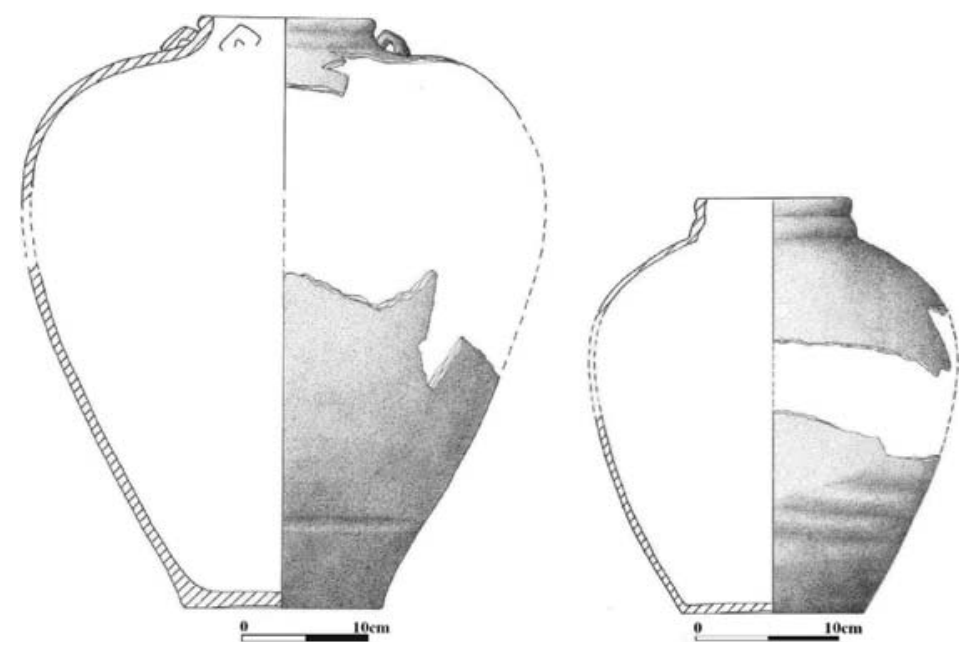

Fig. 12. Jar pots from 0S6. 

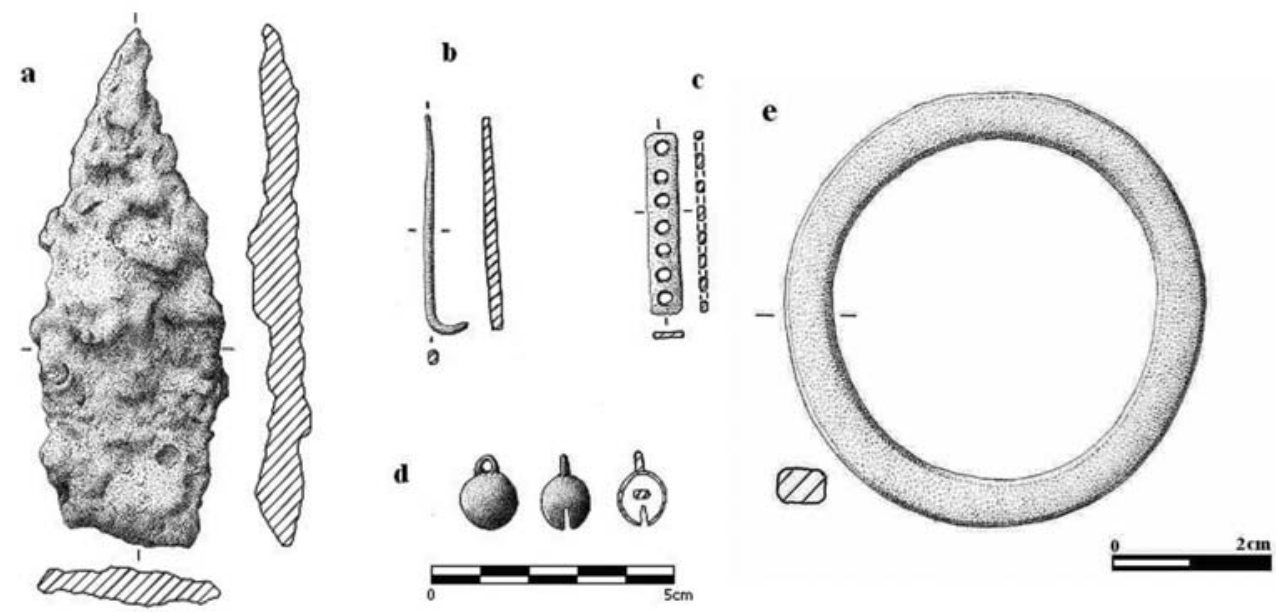

Fig. 13. Various metal artifacts unearthed from Saqacengalj ( $a$ : iron tool; $b$ : needle; $c$ : plate with holes; $d$ : bell; $e$ : brace).

Table 6. Possible Imported Goods Unearthed from Units

\begin{tabular}{|c|c|c|c|c|c|c|c|c|}
\hline \multicolumn{3}{|l|}{ BRONZE } & \multicolumn{3}{|c|}{ IRON } & \multicolumn{3}{|c|}{ OTHER } \\
\hline TYPE/UNIT & OSI & 0s6 & TYPE/UNIT & OSI & 0s6 & TYPE/UNIT & OSI & 0s6 \\
\hline buckle hook & 1 & - & point & 2 & 2 & bead & - & 18 \\
\hline needle with hook & 1 & - & knife & - & 1 & & & \\
\hline plate with single hole & 1 & - & pan plate & - & 4 & & & \\
\hline plates & 2 & - & unknown & - & 2 & & & \\
\hline plates with hook & 1 & - & plate & 3 & 34 & & & \\
\hline rectangular plate with holes & - & 13 & waste & $5061.5 \mathrm{~g}$ & $44 \mathrm{~g}$ & & & \\
\hline bell & - & 4 & & & & & & \\
\hline brace & - & 4 & & & & & & \\
\hline
\end{tabular}

total of 82 pieces of these material goods. The number of distinct types and the quantities of these goods in the two units are relatively different.

Although it is still not entirely certain that all these remains were imported and can be unequivocally regarded as prestige goods by the inhabitants, and some further analysis is needed, the variation of the distribution of these remains in the units suggests restricted accessibility to special resources, and therefore that power and status associated with control of these resources were relatively differentiated between the two households. Examining the shapes of the structures represented by the two units, OS1 is vertically rectangular and OS6 is horizontally rectangular; therefore, it can be argued that the variation in the distribution of these restricted goods may imply differences in the power and status of the occupants of the the houses. This analysis further supports the social differentiation indicated from the patterns in the distribution of house sizes and house shapes.

Strong cultural canons (in an egalitarian group) or a desire to form an identity that will differentiate them from other groups or subgroups might be an alternative interpretation to the hypothesis of status differentiation offered for these highly patterned 
house structures. However, what is the interior mechanism that leads cultural canons to be strongly practiced or group identity to be strongly established and presented, besides social constraint and social differentiation? The diversity in the function of house structures might as well have led to the variation in house size and the distribution of imported goods. A too limited sample size results in a less convincing interpretation of the meaning of variation in the distribution of imported goods within house units. Therefore, in future studies, there is a need for gaining a better understanding of the differences between mechanisms for strong social constraints and strong cultural canons or group identity in producing patterned household remains, as well as verifying the function of house structures, obtaining larger sample sizes, and collecting other relevant evidence to further substantiate these arguments.

\section{CONCLUSION}

As found in this study, the settlements at Saqacengalj, Cacevakan, Aumagan, Old Lai-yi, and other North Pai-wan settlements share some common characteristics. They are as follows: the settlements were located in the mildly sloped areas in the mountain woodlands; stone slate house structures (floors, walls, roof, poles, and even internal structures) were arranged parallel to numerous slope terraces and were adjacent to one another, side by side sharing a side wall, usually set against the slope and facing the valley; and there was an L-shaped (long leg) cross section of the foundation of the structures formed by cutting into the terrace and building the rear and side walls against excavated portions. According to oral history and the genealogy of certain families of their descendants, there have been 11 or 13 generations at Old Lai-yi since the settlement was first built (approximately a period of 250 to 350 years; Wu 1994: 68). Saqacengalj might also have been occupied for 350 years. These dates make it possible for these characteristics to have been present at Saqacengalj, Cacevakan, Aumagam, and Old Lai-yi when they were built about 350 years ago or even much earlier, and lasting until the settlements were finally abandoned. The common features of the settlements emphasize Pai-wan tradition and cultural continuity, which were carried out and shared among subgroups in different times and different areas.

The shape of the house (vertically rectangular versus horizontally rectangular), the size of the front yard, whether or not a platform was attached to the house structures, and the shape of the settlement layout differentiates the configuration pattern of the settlement and house structures of the three South Pai-wan sites included in the study from that of the North Pai-wan settlements. Old Lai-yi and other North Pai-wan ${ }^{2}$ settlements have houses with horizontally rectangular shapes with a narrow front yard and without a platform, which was the general and common configuration of the house structures in this area. The settlements purposely used an attached platform to symbolize high social status. The three South Pai-wan settlements, on the other hand, erected houses with a vertically rectangular shape, a front yard, and a platform on a broad terrace as the ideal, normal pattern. This suggests the separate development and localization of each Pai-wan subgroup in their respective areas with regard to these cultural norms. It can be inferred that these distinctive characteristics were already developed in southern Taiwan by at least about 350 years ago, and perhaps much earlier. People brought these characteristics with them and passed them on from generation to generation through daily social practices, until they abandoned the settlements and built new ones. 
In this study, the settlement patterns and house structures at the three studied sites were examined. The results show that patterns, such as house shape, a big front yard, a platform attached, and inner features, show considerable constancy within individual settlements. The size distribution of the house structures is highly clustered within a certain range and the distribution of imported or prestige goods are diverse. Corroborated by oral history, and from the perspectives of social and daily practices, the phenomenon might be interpreted to mean that certain strictly rule-bounded social practices shaped the inhabitants' perception of how settlement and house structures should be constructed, and these practices constrained their choices. This could further indicate that a certain level of social differentiation developed at the three settlements. Social constraints result from a certain level of social differentiation and centralization of power that are transmitted through social practices and that shape the regulation and coordination of the construction of settlement patterns and house structures that follow rigid templates and endure over time. In addition, social identity and social memory might have been repeatedly constructed through establishing settlements at different times and in different areas.

As mentioned above, the attached structures, symbolic poles, engraved decorative structural features, and Ficus microcarpa trees, as well as the size of the houses and front yards and the presence or absence of the front platform, had been used to determine the social status and wealth of the inhabitants of Old Lai-yi and other North Pai-wan settlements (Chiang 2002; Chiang and Li 1995; Chijilwa 1937; S. Hsu 1996; Kau 2003; C. Li 1994; Y. Li and C. Wu 1982; Lin 1994). Consequently, although both groups might have had the same stratified social system, the Kau-shi, or certain other South Pai-wan groups, and the North Pai-wan ${ }^{3}$ used different ways, in some aspects, to address the variations on social status and wealth. Whether the characteristics mentioned above were also used to indicate who the chief was or to show the status of the inhabitants of the three settlements studied and of the other South Pai-wan groups is still unknown due to the incomplete preservation of the sites. However, unlike the North Pai-wan group, the size of the front yard and the presence or absence of a platform was not used to determine the social status of the inhabitants of the three settlements. Nevertheless, the highly clustered distribution of house sizes and the highly consistent house shape illustrate a certain social control practiced over these aspects, which may differ from those at the North Pai-wan settlements. The shape (vertical versus horizontal rectangular) at these three sites may also be interpreted as an indicator of social status because the largest ones were horizontally rectangular in shape and not vertically rectangular, as most of the houses were. These aspects might also indicate that the mechanisms or processes involved in the development of centralization and power control of the North and South Pai-wan groups were different. These suggestions can be addressed in future studies.

It could be speculated that, for the North Pai-wan settlements and the studied South Pai-wan settlements, the shape of the house structures, the size of the front yards, the presence or absence of a platform, and the direction a settlement extended are different and that these also shaped the people's sense of direction, their concept of space, the way their bodies moved, the way they organized their daily activities, and the interaction with others both inside and outside a house in different ways. The correspondence between the shape of the house structures and settlement layout can also indicate that certain conceptions and construction of space between subgroups were different. The diversity of these cultural aspects of the different subgroups indicates 
that these cultural practices had been subjected to change in certain contexts or strategies by which each subgroup adapted to its own historical processes and environments. This can guide further research in the future with a more detailed spatial analysis to explore the practice of daily tasks in domestic and public areas.

This study observed these three sites from the perspective of settlement configuration and house structures. The conclusion is that, in terms of the concept of social practice, the properties of social systems at the settlements might be interpreted by revealing certain restrictedly repeated patterns of settlement configuration and house structure. Social identities and social memory were also constructed through social practices in these settlements and house structures by Pai-wan groups at different times and in different areas. The results also show that these three settlements share common characteristics and patterns with other Pai-wan settlements. However, some characteristics and patterns shared by these three sites were different from those of the North Pai-wan settlements. If we can take these three settlements as representatives of certain times of the Kau-shi and of a certain part of the South Pai-wan groups, ${ }^{4}$ then the common characteristics and patterns at these three sites that are shared by other North Pai-wan groups may show a common tradition and cultural continuity of Paiwan through different times and in different areas. In addition, the similarities shared by the three settlements, but not by those in North Pai-wan, exhibit continuity in the Kau-shi and the localization of these cultural aspects in South Pai-wan, further indicating that the Pai-wan subgroups might have developed distinctive cultural and social practices in these areas. Moreover, this indicates that these cultural aspects could have been modified under certain contexts or strategies, which the subgroups carried out in order to adapt to their respective historical and environmental processes. Were these characteristics brought by people from where they originated, or were they developed while the people adapted to their local environments or to new circumstances after they immigrated to the new places? Moreover, the traditional view of regarding North Pai-wan as being more representative of the original and traditional Pai-wan culture needs to be reconsidered and debated. These directions for research are significant targets for further study.

\section{ACKNOWLEDGMENTS}

Gratitude is extended to Kau-shi villagers, friends, and students who helped in carrying out the fieldwork and made comments on the article to fulfill this study, and to the Center of Austronesian Cultural Study, National Taiwan University, for offering the grants that made the research possible.

\section{ENDNOTES}

1. Due to the destruction of some structure units, the restriction on the accessibility, or the poor visibility of certain areas, there are only some slates spread on the grounds, and all of the structures could not be identified to gain a precise number for the whole site.

2. Old Lai-yi has been regarded as the representation of the settlements of North Pai-wan and even of all of Pai-wan, but there has been no detailed corresponding data on other North Pai-wan settlements recorded or published in order to determine the extent of representation.

3. Old Lai-yi and other North Pai-wan groups were ranked societies, which are reported extensively by ethnographic studies.

4. Although K. C. Li (1985) and K. T. Li (2004) have also studied some sites with slate house structures in nearby areas, they offer no corresponding information for comparison, and thus this cannot be included in the discussion. 


\section{REFERENCES CITED}

CHEN, MAA-LING 陳瑪玲

2005 《高士與其石板屋舊社聚落調查研究報告》, 台北 (The Report of the Investigation of Kaushi and its Old Settlement with Stone Slate Houses, unpublished)

2008 Settlement patterns at Saqacengalj, a slate house settlement in southern Taiwan. Asian Perspectives $47(2): 210-241$.

2010 Interpreting the social meaning of different shapes of house structures by examining the flow of resources: A case study in Saqacengalj, southern tip of Taiwan. Archaeometry 52(6) :10571078 .

Chiang, BIEN 蔣斌主編, ED.

2002 《番族慣習調查報告書 第五卷排灣族》, 台灣總督府臨時台灣舊貫調查會原著, 中央 研究院民族學研究所 (An Investigatory Report on Aboriginal Tradition, vol. 5: Pai-wan Group). Taipei: Ethnology Institute of Academic Sinica.

ChiAng, Bien AND CHING-Yi Li 蔣斌 李靜怡

1995 《排灣族家屋的空間結構與意義》, 黃應貴編, 《空間、力與社會》, 中央研究院民族 學研究所 (The spatial organization and meaning of household of the Pai-wan group), in Space, Power, and Society: 167-212, ed. Yin-kuai Hong. Taipei: Ethnology Institute of Academic Sinica.

Chien, Jui-Hung 簡瑞宏

1995 《排灣族原住民居住空間構成之研究--以屏東縣七佳聚落為例》, 逢甲大學建築及都 市計畫所碩士論文 (A Study of the Constitution of Living Space of Taiwanese Aborigines: A Case Study in Chi-Chai, Ping-Tou District). Unpublished thesis. Department of Architecture and Rural Planning, University of Fou-chai, Tai-chun.

Chijilwa, Suketaro 千千岩助太郎

1937 《台灣高砂族住家の研究, 第一報(總論, 排灣族)》, 台灣建築會出版。(Studies on the House Structure of Taiwanese Aboriginal Groups: Pai-wan Group). Taipei: Society of Taiwan Architecture.

Costin, Cathy L., and Melissa B. Hagstrum

1995 Standardization, labor investment, skill, and the organization of ceramic production in late prehistoric highland Peru. American Antiquity 60(4):619-639.

Hodder, Ian, And Craig Cessford

2004 Daily practice and social memory at Catalhoyuk. American Antiquity 69(1): 17-40.

$\mathrm{HsU}, \mathrm{KAU}-\mathrm{MIN}$ 許功明

1993 排灣族古樓村喪葬制度之變遷, 《人觀、意義與社會, 黃應貴編》, 中央研究院民 族學研究所 (The change in burial system of Kou-lou village, Pai-wan), in The Concept of the Person, Meaning, and Society: 389-469, ed. Ying-kuei Huang. Taipei: Ethnology Institute of Academic Sinica.

HSU, SHENG-FA 許勝發

1996 《傳統排灣族群北部式家屋裝飾初步研究》, 成功大學建築所碩士論文 (An initiate study on traditional household decoration of northern Pai-wan). Unpublished thesis. Department of Architecture, University of Chen-koun, Tai-nan.

HuAng, CHUN-MiN 黃俊銘

1982 《排灣族北部型住屋變遷之研究》, 成功大學建築所碩士論文 (A Study on the Change in House Structure of northern Pai-wan). Unpublished thesis. Department of Architecture, University of Chen-koun, Tai-nan.

HUANG, YING-KUEI 黃應貴

1995 《空間、力與社會》, 中央研究院民族學研究所 : 台北 (Space, Power, and Society). Taipei: Ethnology Institute of Academic Sinica.

Johnson, Gregory A.

1980 Rank-size convexity and system integration: A view from archaeology. Economic Geography $56(3): 234-247$.

KAU, TO-SHAOU 郭東雄

2003 《台灣排灣族七佳舊社住居文化之研究》。臺南師範學院鄉土文化研究所碩士論文 (The Study on House and Culture of Chi-chai: A Pai-wan Old Settlement). Unpublished thesis. Department of Folk Culture Study, Tai-nan Normal College, Tai-nan. 
LI, CHING-YI 李靜怡

1994 《排灣族舊來義社住屋的復原與詮釋》, 東海大學建築所碩士論文 (The Reconstruction and Interpretation of the House Structure of Lai-yi Abandoned Settlement, Pai-wan Group). Unpublished thesis. Department of Architecture, University of Tou-hai, Tai-chun.

LI, KUANG-CHOU 李光周

1985 《墾丁國家公園考古調查報告》, 國立台灣大學人類學系 (Report of Archaeological Investigations in the Kenting National Park on the Southern Tip of Taiwan). Taipei; National Taiwan University Press.

LI, KUANG-TI 李匡悌

2004 《恒春半島石板屋聚落遺址的空間關係研究》, 「2004年臺灣考古工作會報」會議 論文, 中央研究院人文社會科學研究中心 (A Study on Spatial Relationship among Slate House Settlements in the Hunchun Area). Paper presented at the Annual Meeting of Taiwan Archaeology 2004, Research Center for Humanities and Social Sciences.

Li, YI-YUAN AND CHOU-YI WU李亦園、文崇一

1982 《台灣山地建築文化: 台灣山地文化園區規劃報告第二冊》, 中央研究院民族學研 究所 (The Architectural Cultures of Taiwanese Aborigines: A Report on the Design of the Cultural Exhibition Park of Taiwanese Aborigine, vol. II). Taipei: Ethnology Institute of Academic Sinica.

LI, YI-YUAN AND ChOU-Yi Wu 林宏益

1994 《生存空間的澄明與詮釋--以排灣族caia?abus社為例》, 東海大學建築所碩士論文 (Verification and Interpretation of Living Space-Case Study on Caia?abus, Pai-wan). Unpublished thesis. Department of Architecture, University of Tou-hai, Tai-chun.

Marshall, Yvonne

2008 The social lives of lived and inscribed objects: A Lapita perspective. Journal of the Polynesian Society 117(1):59-101.

Trubitt, Mary Beth

2000 Mound building and prestige goods exchange: Changing strategies in the Cahokia chiefdom. American Antiquity 65(4):669-690.

TSENG, Chen-Min 曾振名

1991 《台東縣魯凱、排灣族舊社遺址勘查報告》(An Investigatory Report on Old Abandoned Settlements of Lu-kai and Pai-wan in Tai-tou District).

Wu, Cheng-HOUng 吳政隆

1994 《排灣族來義聚落與空間之研究》, 東海大學建築所碩士論文 (The Study on Settlement and Space of Old Lai-yi). Unpublished thesis. Department of Architecture, University of Tou-hai, Tai-chun.

\begin{abstract}
Archaeologists have recently suggested that the practice of daily and social life is the prime aspect by which social rules, meanings, and relations of power are embedded for social control. A high degree of system (either political or economic) integration indicates a strong, centralizing, and coordinating control and constraint on practice of mundane life and the flow of resources that eventually will shape the development of settlement patterns as well as house structure and size, and the flow of resources. This study focuses on analyzing evidence, such as the settlement configuration, house shape and size, and distribution of imported or prestige goods, to detect the existence of social differentiation in aboriginal settlements of Taiwan during the Protohistoric period. KEYWORDS: spatial analysis, Taiwan, settlement pattern, Pai-wan, social differentiation.
\end{abstract}

